\title{
Preparation Method of Spherical and Monocrystalline Aluminum Powder
}

\author{
Mateusz Skalon ${ }^{1, *}$, Marek Hebda ${ }^{2}{ }^{(0)}$, Ricardo Buzolin $\left.{ }^{1}{ }^{(}\right)$, Gernot Pottlacher ${ }^{3}$, Stefan Mitsche ${ }^{4}$ \\ and Christof Sommitsch ${ }^{1}$ (D) \\ 1 IMAT Institute of Materials Science, Joining and Forming, Graz University of Technology, \\ Kopernikusgasse 24, 8010 Graz, Austria; ricardo.buzolin@tugraz.at (R.B.); \\ christof.sommitsch@tugraz.at (C.S.) \\ 2 Institute of Materials Engineering, Cracow University of Technology, 24 Warszawska ave, \\ 31-155 Cracow, Poland; mhebda@pk.edu.pl \\ 3 Institute of Experimental Physics, Graz University of Technology, Petersgasse 16, 8010 Graz, Austria; \\ pottlacher@tugraz.at \\ 4 Institut für Elektronenmikroskopie und Nanoanalytik, Steyrergasse 17/III, 8010 Graz, Austria; \\ smitsche@tugraz.at \\ * Correspondence: mateusz.skalon@tugraz.at; Tel.: +43-(0)-316-973-4305
}

Received: 5 March 2019; Accepted: 20 March 2019; Published: 23 March 2019

\begin{abstract}
This paper presents a new production method for a spherical and monocrystalline aluminum powder. Aluminum powder of irregular particle shapes was mixed with silica nanoparticles and heated to a temperature above the melting point of aluminum. Due to its molten state, high surface tension, and poor wettability, the aluminum particles were transformed into liquid and spherical droplets separated by silica nanoparticles. The spherical shape was then retained when the aluminum particles solidified. The influence of the processing temperature on the particle shape, phase composition, and microstructure was investigated. Moreover, calorimetric, $X$-ray diffraction, grain size, and scanning electron microscopy with electron backscatter diffraction (SEM-EBSD) measurements of the particles' microstructure are presented. It is proven that, by this means, a spherical and monocrystalline aluminum powder can be efficiently created directly from an air-atomized irregular powder. The observed phenomenon of particles becoming round is of great importance, especially when considering powder preparation for powder-based additive manufacturing processes.
\end{abstract}

Keywords: aluminum; spherical particles; powder; crystal; EBSD

\section{Introduction}

A large and growing interest is focused on powder-based additive manufacturing, especially among those industrial fields where the method can be of great importance, such as aviation or high-end motor vehicles [1]. For individual industrial applications, such as the manufacture of metal parts through metal injection molding, selective laser melting (SLM) or combustion, characteristics such as shape and particle-size distribution are basic requirements among many others, e.g. bulk chemical composition, surface composition, and cohesion [2-5]. It is commonly known that spherical powders are characterized by a higher apparent density and flowability compared to those of irregular shapes [2-7]. Commonly used industrial methods of manufacturing spherical (or nearly spherical) aluminum powders are heretofore based on thermal spraying, plasma spraying, or other physical means of disrupting the molten metal into separate droplets $[3,8,9]$. These widely used powder manufacturing methods are characterized by some deficiencies, including high energy consumption and their complexity. The products are also often characterized by a wide particle-size distribution 
and variable particle microstructure, which frequently does not meet the requirements for use. Plasma atomization is currently the only industrial powder post-processing method that allows rounding of the powder by using precursor powder as a feedstock. In this process, the powder is rounded due to the surface tension of the liquid metal droplet as it solidifies in the presence of an inert gas. Since the process of droplet formation in these processes is dynamic, the shape of the resulting particles is not always spherical. The outcome is strongly dependent on the process parameters, physical properties of the melt, and properties of the surrounding gaseous medium. When a droplet of a molten metal contacts a solid material, the contact angle is strongly dependent on the interfacial free energies-solid-vapor $\gamma_{S V}$, liquid-vapor $\gamma_{L V}$ and solid-liquid $\gamma_{S L}$-and is calculated using Young's equation (Equation (1)):

$$
\cos \theta=\left(\gamma_{S V}-\gamma_{S L}\right) / \gamma_{L V} \text {. }
$$

In the case of low wettability, the contact angle is higher than $90^{\circ}$ and the liquid droplet tends to adopt a spherical form. The surface tension of silica is considerably lower than that of molten aluminum at the melting points $340 \mathrm{mN} \cdot \mathrm{m}^{-1}$ [10] and $871 \mathrm{mN} \cdot \mathrm{m}^{-1}$ [11], respectively. Therefore, either no or limited wetting should appear, as reported by Sobczak et al. [12]. Silica is also characterized by a higher melting point than aluminum: $1973 \mathrm{~K}$ [13] and $933 \mathrm{~K}$, respectively [14]. In this paper, we report a secondary powder-processing method allowing for the rounding of irregular powder particles by utilizing the combination of the properties listed above. The method is based on mixing aluminum powder with silica nanoparticles and heating the blend above the melting point of aluminum. Silica is used as a separator-it is introduced in order to prevent fusing of the neighboring molten aluminum particles. A similar strategy was implemented in the process of growing GaN crystals [11], and in the course of this process, the particles were rounded; graphene was utilized as the separator [15]. The latter, however, is lacking both an adequate explanation of how a processing temperature is selected and also a microstructure analysis.

\section{Materials and Methods}

Air-atomized aluminum powder delivered by Benda Lutz $\mathrm{AG}^{\circledR}$ (Skawina, Poland) of commercial grade AG 63 (Al: $99.65 \mathrm{wt} . \%$, Fe + Cu: $0.2 \mathrm{wt} . \%$, Si: $0.15 \mathrm{wt} . \%,<63 \mu \mathrm{m}$ ) was used as the base material. The base powder was mixed with $20 \mathrm{wt} . \%$ addition of silica nanopowder of $400 \mathrm{~nm}$ particle size and $99.9 \mathrm{wt} . \%$ purity. Silica was used as a separator among the aluminum particles in order to prevent their agglomeration at elevated temperatures (including temperatures higher than the melting point of the aluminum particles). The blend was prepared by $2 \mathrm{~h}$ of mixing of the compounds using a turbula-type mixer under standard conditions. A Netzsch DSC 404 (NETZSCH-Gerätebau GmbH, Selb, Germany) calorimeter was utilized in order to investigate inter-phase or chemical reactions that occurred in the mixed powders and their oxides. Differential scanning calorimetry (DSC) tests, in $\mathrm{Al}_{2} \mathrm{O}_{3}$ crucibles, were carried out in an atmosphere of pure argon (99.9999\%) according to the following temperature profile: heating and cooling rate of $10 \mathrm{~K} / \mathrm{min}$, isothermal time of $10 \mathrm{~min}$, and two isothermal temperatures of 1023 and $1423 \mathrm{~K}$. The experimental set was composed of 4 sets of samples: (A) reference air-atomized $\mathrm{Al}$ powder; (B) $\mathrm{Al}$ powder heated up to $1023 \mathrm{~K}$; (C) $\mathrm{Al}+20 \mathrm{wt} . \%$ $\mathrm{SiO}_{2}$ heated up to $1023 \mathrm{~K}$, and (D) $\mathrm{Al}+20 \mathrm{wt} . \% \mathrm{SiO}_{2}$ heated up to $1423 \mathrm{~K}$. After the heat treatments, the powders were cleaned in distilled water. The cleaning procedure consisted of 3 cycles of $\sim 5 \mathrm{~min}$ each using an ultrasound cleaner, followed by $1 \mathrm{~min}$ of holding time to guarantee sedimentation of the aluminum particles. After sedimentation, the water was drained away and the powder was dried at $353 \mathrm{~K}$ using a ceramic heating plate-IKA C-MAG HS7 (IKA®Werke GmbH \& Co. KG, Staufen, Germany). The particle-size distribution was checked using the Laser Particle Sizer Analysette 22 MicroTec Plus (Fritsch GmbH, Idar-Oberstein, Germany). A portion of the powder was carefully mixed with conductive Bakelite: Struers PolyFast (Struers GmbH, Puch, Austria) and was hot embedded (4 min of cure time at $453 \mathrm{~K}$ and $25 \mathrm{MPa}$ ) for metallographic preparation. After grinding using $\mathrm{SiC}$ paper from 500 to 2000 grid with a force of $5 \mathrm{~N}$, the specimen was polished using a diamond suspension of $1 \mu \mathrm{m}$ and a force of $5 \mathrm{~N}$, followed by polishing in Aluminum Oxide Polishing Suspension (OPS), 
of $0.05 \mu \mathrm{m}$ and also using a normal force of $5 \mathrm{~N}$. A final polishing using an acidic alumina suspension in a Buehler Vibromet 2 vibro-polisher (Buehler, Lake Bluff, IL, USA) was performed to guarantee a corrosion- and deformation-free surface for electron backscatter diffraction (EBSD) measurement.

The microstructural features of the powder particles were determined with scanning electron microscopy (SEM). Energy-dispersive X-ray spectroscopy (EDX spectroscopy or EDXS) was used for evaluation of the chemical composition. X-ray diffraction measurements were performed using a Siemens D5005 diffractometer (Siemens, Munich, Germany). EBSD measurements were performed to investigate the crystallinity of the powder particles. A field emission gun (FEG) TESCAN Mira3-SEM (TESCAN Brno s.r.o., Brno, Czech Republic) equipped with an EDX spectrometer, a Hikari detector and the OIM-Data Analysis v.8 software ${ }^{\circledR}$ (Ametek, Inc. Berwyn, PA, USA) package for EBSD analysis were used. The data points were cleaned using three clean-up steps: (i) grain dilation using a grain tolerance angle of $12^{\circ}$ and a minimum grain size of $1.3 \mu \mathrm{m}$, followed by (ii) grain confidence index (CI) standardization using a grain tolerance angle of $12^{\circ}$ and a minimum grain size of $0.5 \mu \mathrm{m}$, and finally (iii) the neighbor CI correlation clean-up procedure using a minimum confidence index of 0.2 . The minimum grain size was chosen as $2 \mu \mathrm{m}$ with a confidence index of 0.3 . The high-angle boundaries were set to be greater than $12^{\circ}$ while the small-angle boundaries were set as $<12^{\circ}$ but $>2^{\circ}$.

\section{Results and Discussion}

Figure 1a-f depicts the results of DSC measurements of samples B, C, and D. The tests showed that for sample $\mathrm{D}$, above the melting temperature of aluminum, an exothermic peak is observed (Figure 1e). According to West and Gray [16], gamma alumina $\left(\gamma-\mathrm{Al}_{2} \mathrm{O}_{3}\right)$ crystallizes at $1253 \mathrm{~K}$, resulting in an exothermic reaction. Moreover, the first peak from the recorded doublet (III) reflects an exothermic redox reaction between the elemental aluminum and silica according to Equation (2):

$$
4 \mathrm{Al}+3 \mathrm{SiO}_{2}=2 \mathrm{Al}_{2} \mathrm{O}_{3}+3 \mathrm{Si}
$$

Combined exothermic reactions are visible as a double-peak (III) (Figure 1e). In the cooling curve, a low-energy exothermic peak (VII) that follows the aluminum solidification peak is observed (Figure 1f). This peak is attributed to solidification of an Al-Si near-eutectic phase [17].

No thermal effects were observed in the temperature range between the melting temperature of aluminum (I) and the double peak (III) (Figure 1e). Therefore, this range was selected as a potentially safe temperature region for aluminum powder processing (between 968.9 and $1122.2 \mathrm{~K}$ ). Based on data presented by Pottlacher et al. [14], the surface tension of liquid aluminum reaches its highest value $\left(872.7 \mathrm{mN} \cdot \mathrm{m}^{-1}\right)$ at temperatures slightly higher than the melting point. In order to ensure that the powder is completely molten and the surface tension is sufficiently high, the processing temperature was set at $1023 \mathrm{~K}$, which is $54.1 \mathrm{~K}$ higher than the melting point and $99.2 \mathrm{~K}$ lower than the observed initiation of crystallization and redox $\left(\mathrm{Al}+\mathrm{SiO}_{2}\right)$ reactions. At $1023 \mathrm{~K}$, the surface tension of aluminum is between 860.0 and $866.3 \mathrm{mN} \cdot \mathrm{m}^{-1}$ and decreases with increasing temperature [14].

The combination of the listed factors and conditions resulted in transforming the blend of solid particles $\left(\mathrm{Al}\right.$ and $\left.\mathrm{SiO}_{2}\right)$ into the mixture of liquid aluminum droplets separated with solid silica nanoparticles. In this state the aluminum particles were rounded due to the high wetting angle induced by the presence of silica nanoparticles.

The DSC heating curve of the sample C (Figure 1c) exhibited no signs of any presence of other phases than face-centered cubic aluminum, while the cooling curve (Figure 1d) shows a peak of small intensity, attributed to an Al-Si near-eutectic phase. Such a peak was not found in the DSC curve of sample B (Figure 1a,b, when no silica was present in the blend). This finding suggests that the reaction according to Equation (2) occurred slowly during the annealing time, but it was not present in the as-produced blend. Table 1 presents the specific temperatures of registered reactions. 

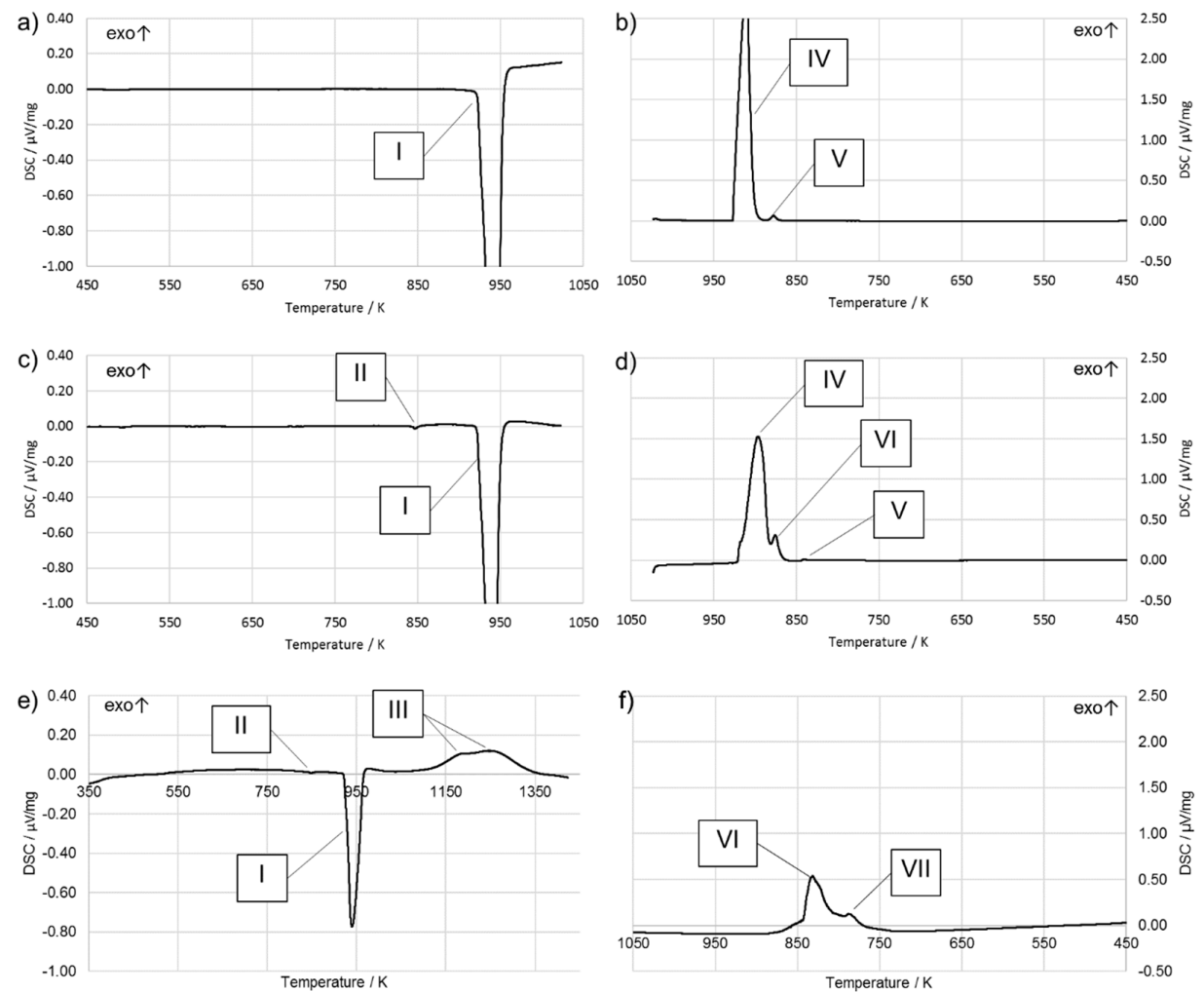

Figure 1. Representative differential scanning calorimetry (DSC) curves for (a) heating stage of sample B; (b) cooling stage for sample B; (c) heating stage for sample C; (d) cooling stage for sample C; (e) heating stage for sample D; (f) cooling stage for sample D.

Table 1. Description of the measured thermal effects obtained using DSC for different blends.

\begin{tabular}{|c|c|c|c|c|c|}
\hline Stage & Peak Code & Onset Temp./K & $\begin{array}{l}\text { Maximum } \\
\text { Intensity } \\
\text { Temp./K }\end{array}$ & $\begin{array}{l}\text { Endset } \\
\text { Temp./K }\end{array}$ & Effect Description \\
\hline $\begin{array}{c}\text { Sample B } \\
\text { Heating to } 1023 \mathrm{~K}\end{array}$ & I & 920.7 & 946.9 & 963.0 & Melting of Al particles [14] \\
\hline \multirow{2}{*}{$\begin{array}{l}\text { Sample B Cooling } \\
\text { from } 1023 \mathrm{~K}\end{array}$} & IV & 927.1 & 910.8 & 886.1 & \multirow{2}{*}{$\begin{array}{l}\text { Solidification of } \mathrm{Al} \\
\text { particles }[14,18] \\
\text { Al powder impurities }\end{array}$} \\
\hline & $\mathrm{V}$ & 886.1 & 887.5 & 868.3 & \\
\hline \multirow{2}{*}{$\begin{array}{c}\text { Sample C } \\
\text { Heating to } 1023 \mathrm{~K}\end{array}$} & I & 921.4 & 940.8 & 951.8 & \multirow{2}{*}{$\begin{array}{l}\text { Melting of Al particles [14] } \\
\text { Al powder impurities }\end{array}$} \\
\hline & II & 571.4 & 573.4 & 581.8 & \\
\hline \multirow{3}{*}{$\begin{array}{l}\text { Sample C } \\
\text { Cooling from } \\
1023 \mathrm{~K}\end{array}$} & IV & 920.7 & 896.1 & 881.6 & \multirow{3}{*}{$\begin{array}{c}\text { Solidification of Al particles } \\
\text { [14,18] } \\
\text { Solidification of Al-Si } \\
\text { eutectics [17] } \\
\text { Al powder impurities }\end{array}$} \\
\hline & VI & 881.6 & 875.3 & 867.2 & \\
\hline & $\mathrm{V}$ & 845.5 & 841.0 & 833.7 & \\
\hline \multirow{3}{*}{$\begin{array}{c}\text { Sample D } \\
\text { Heating to } 1423 \mathrm{~K}\end{array}$} & II & 844.1 & 847.6 & 854.3 & \multirow{3}{*}{$\begin{array}{l}\text { Al powder impurities } \\
\text { Melting of } \mathrm{Al} \text { particles [14] } \\
\mathrm{Al}+\mathrm{SiO}_{2} \text { redox reaction } \\
\text { followed by } \mathrm{Al}_{2} \mathrm{O}_{3} \\
\text { formation }[16]\end{array}$} \\
\hline & I & 921.3 & 939.9 & 968.9 & \\
\hline & III & 1122.2 & $\begin{array}{l}1181.0 / 1248.3 \\
\text { (double peak) }\end{array}$ & 1347.8 & \\
\hline $\begin{array}{l}\text { Sample D } \\
\text { Cooling from } \\
1423 \mathrm{~K}\end{array}$ & VI and VII & 873.4 & $\begin{array}{l}832.1 / 787.8 \\
\text { (double peak) }\end{array}$ & 728.8 & $\begin{array}{l}\text { Solidification of Al-Si } \\
\text { based particles } \\
\text { [17] followed by } \\
\text { solidification of } \\
\text { Al-AlFeSi-Si ternary } \\
\text { eutectics [19] }\end{array}$ \\
\hline
\end{tabular}

As presented in Table 1, the higher temperature of the heat treatment $(1423 \mathrm{~K})$ visibly shifted the solidification temperature of the aluminum particles to lower temperatures when compared to the sample $C$ heat treated at $1023 \mathrm{~K}$. A similar finding, but exhibiting lower shift values, was also reported by Yang et al. [18]. The early nucleation was attributed to the presence of $\mathrm{Al}_{2} \mathrm{O}_{3}$ which acted 
as nucleation sites during solidification. In the given case, however, the temperature shift was $64.0 \mathrm{~K}$ down to $832.1 \mathrm{~K}$, which resembles the melting point of the Al-Si eutectic (853 K) [20].

In order to clarify the role of $\mathrm{Si}$ in the formation of the low-melting Al-based particles, the presence of $\mathrm{Si}$ in the aluminum particles was investigated using SEM-EDXS. SEM-EDXS line-scans are presented in Figure 2c,d for samples heat treated 1023 and $1423 \mathrm{~K}$, respectively. The presence of a significant amount of $\mathrm{Si}$ in the Al matrix of the particles, for the powder produced at $1423 \mathrm{~K}$, was observed (Figure 2d), which shows a typical microstructure of the Al-Si eutectic phase [20]. Also, the BSE images reveal the formation of a typical eutectic morphology, with a matrix of Al with nearly no Si in a solid solution and neighboring islands of Si. Such a microstructure was not observed in the case of the blend treated at $1023 \mathrm{~K}$ (Figure 2a,c). In that case, the presence of Si in the Al powder particles was not detected via SEM/BSE. The high temperature $(1423 \mathrm{~K})$ allowed diffusion of Si from reduced $\mathrm{SiO}_{2}$ to the liquid $\mathrm{Al}$, and consequently, led to the formation of the Al-Si phase. The former was responsible for the shift in the solidification temperature of the Al from 910.8 to $832.1 \mathrm{~K}$, which corresponds to the formation temperature of near-eutectic phase. Silicon was formed as a result of a redox reaction according to Equation (2), and the products of this reaction can be seen in Figure 2b,d, where a large area of Si was detected.
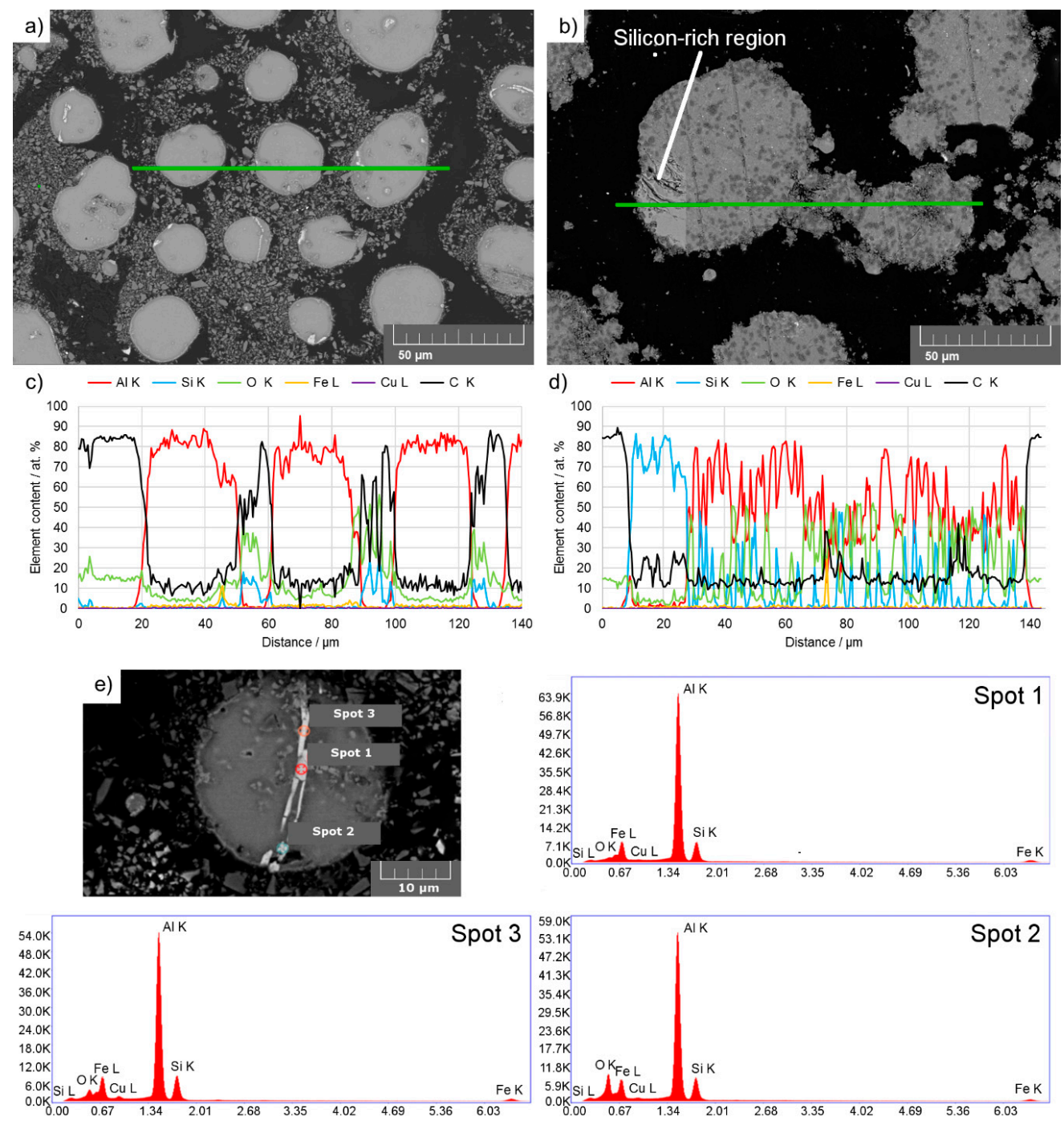

Figure 2. (a) Backscattered electrons (BSE) image of the sample $\mathrm{C}$; (b) BSE image of the $\mathrm{Al}_{2} \mathrm{O}_{3}$ crucible and remnants of sample D; (c) scanning electron microscopy with energy-dispersive X-ray spectroscopy (SEM-EDXS) line-scan as shown in the green line in Figure 2a; (d) SEM-EDXS line-scan as shown in the green line in Figure 2b; (e) point EDXS analysis of sample C. 
The data presented in Table 2 shows that the bright phases visible in Figure 2a,e contain mainly aluminum, silicon, iron, and trace amounts of copper. Gorny et al. [19] described a map of occurrence of AlFeSi intermetallic phases with a dependence on the cooling rate and silicon content in 1000 series aluminum. Based on these observations, bright phases visible in Figure 2a represent both the $\alpha$-AlFeSi and $\beta$-AlFeSi intermetallic phases. Their occurrence is more pronounced the more oxygen is available in the melt [21]. The presence of this phase results in the formation of a limited amount of ternary $\mathrm{Al}-\mathrm{Si}-\mathrm{AlFeSi}$ eutectic, characterized by a slightly lower solidification temperature than the $\mathrm{Al}-\mathrm{Si}$ eutectic phase [19] which was also spotted in DSC tests and described as peak VII.

Table 2. Estimated chemical composition of tested spots presented in Figure 2e. Based on EDXS measurement.

\begin{tabular}{ccccccc}
\hline Measured EDXS Spot & Element & O-K & Fe-L & Cu-L & Al-K & Si-K \\
\hline \multirow{3}{*}{ Spot 1 } & Weight \% & 1.2 & 11.48 & 0.19 & 74.61 & 12.52 \\
& Atomic \% & 2.15 & 5.88 & 0.08 & 79.13 & 12.75 \\
& Error \% & 9.75 & 2.45 & 36.14 & 2.78 & 5.55 \\
\hline \multirow{3}{*}{ Spot 2 } & Weight \% & 10.99 & 11.62 & 0.42 & 65.03 & 11.94 \\
& Atomic \% & 18.38 & 5.57 & 0.18 & 64.5 & 11.38 \\
& Error \% & 6.88 & 3.51 & 18.74 & 2.98 & 5.38 \\
\hline \multirow{2}{*}{ Spot 3 } & Weight \% & 4.2 & 12.99 & 1.2 & 67.71 & 13.9 \\
& Atomic \% & 7.46 & 6.61 & 0.54 & 71.32 & 14.07 \\
& Error \% & 7.78 & 2.76 & 9.6 & 2.98 & 5.43 \\
\hline
\end{tabular}

X-ray diffraction tests (Figure 3) showed that both samples A and C consist of $\alpha$-aluminum and do not differ significantly, except for the presence of a small peak at $38.5^{\circ}$, representing the presence of a small quantity of the Al-Si phase (PDF 41-1222). This supports the assumption of a continuous limited redox reaction, even at temperatures lower than the occurrence of peak III (Figure 1e). While investigating sample $C$, no traces of alumina were found, which means that no extensive oxidation occurred during heat treating and the following cleaning procedures. Sample D, on the other hand shows the presence of aluminum, silica, silicon, and alumina. The presence of both silicon and alumina remains in agreement with redox reaction according to Equation (2). Silicon and aluminum, on the other hand, represent typical phases after the decomposition of the Al-Si eutectic phase. No evidence of the Al-Fe-Si intermetallic phases' presence was found via XRD—most probably due to their scatter and low volumetric fraction.

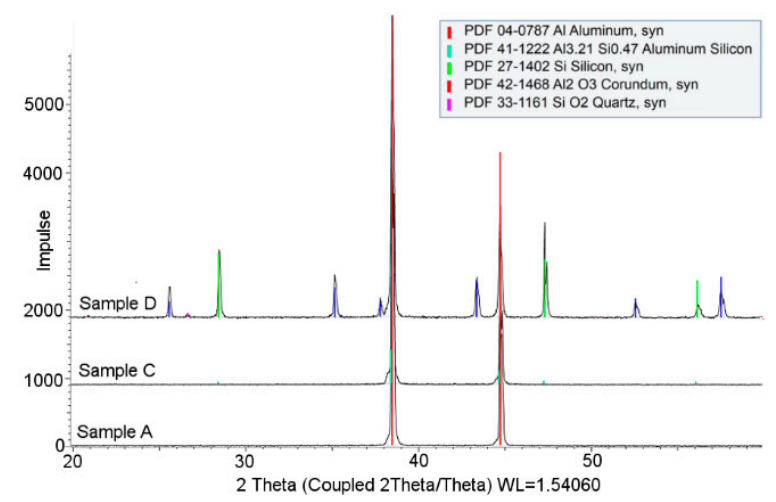

Figure 3. XRD patterns of the samples A, C, and D.

Figure 4 presents the shape and microstructure of the aluminum particles in two stages: as-delivered (Figure 4a,c) and annealed at $1023 \mathrm{~K}$ for $10 \mathrm{~min}$ (Figure $4 \mathrm{~b}, \mathrm{~d}$ ). As mentioned above, the heat treatment performed at $1423 \mathrm{~K}$ activated the redox reaction (peak II) between $\mathrm{Al}$ and $\mathrm{SiO}_{2}$, and the diffusion of the resulting Si into the Al melt. Particles heat-treated at $1023 \mathrm{~K}$ exhibited a spheroidal 
shape due to the combined effects of the molten state, high surface tension [14] and poor wetting angle in contact with silica $\left(99.7-134.6^{\circ}\right)$ [12].
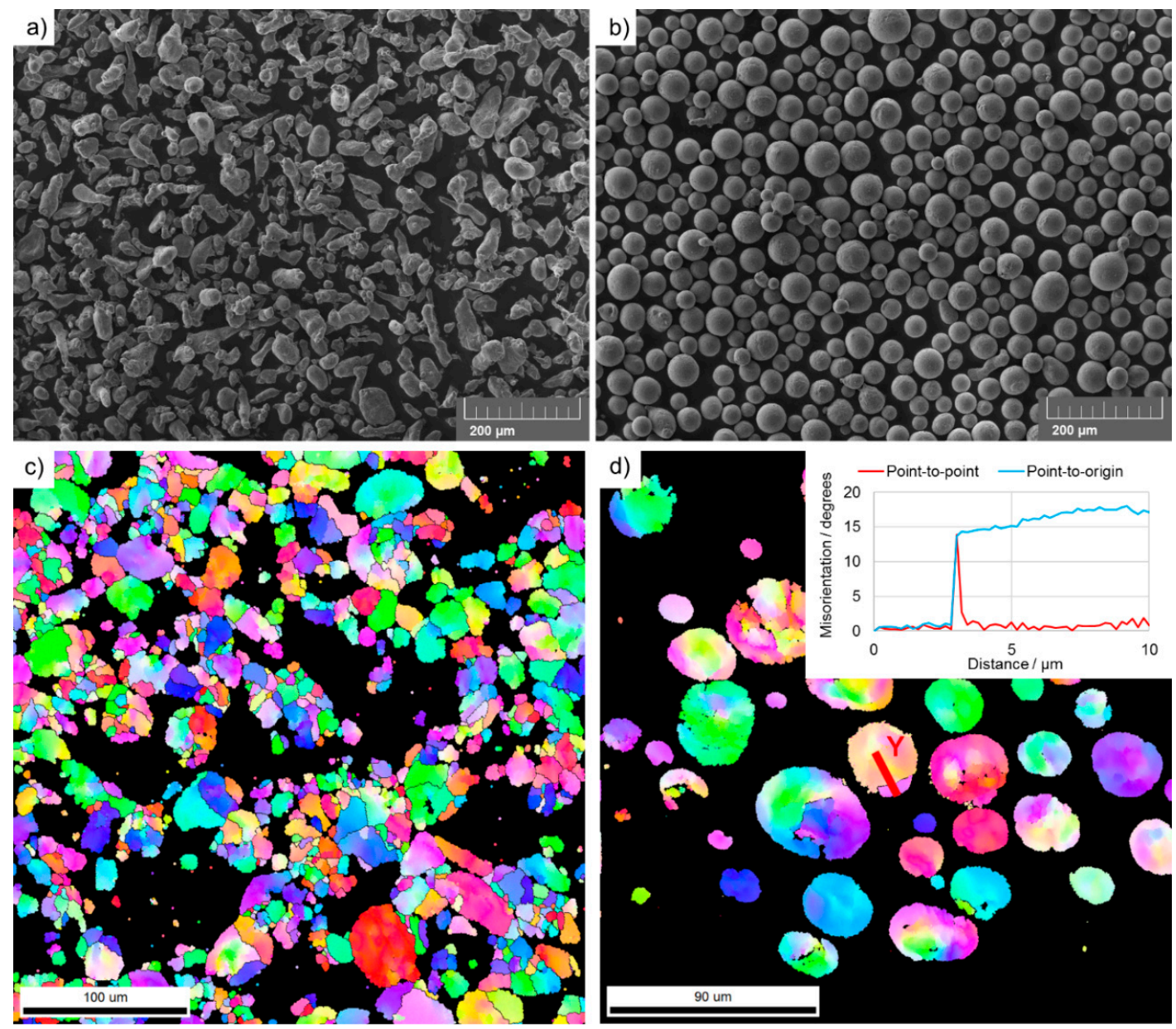

Figure 4. (a) Representative secondary electrons (SE) image of sample A; (b) representative SE image of sample $C$; (c) inverse pole figure map with grain boundaries for sample $A ;(d)$ inverse pole figure map with grain boundaries for sample $\mathrm{C}$ with misorientation profile for the $\mathrm{Y}$ profile.

Since the material was hot-embedded, the powder particles experienced deformation, which is clearly seen by the intensive misorientation spread within the grains of the particles in Figure $4 \mathrm{~d}$. The number of high-angle boundaries, which indicates the degree of mono or polycrystallinity, is small in Figure $4 \mathrm{~d}$. As can be seen in the misorientation angle profile in Figure $4 \mathrm{~d}$, the highlighted boundary exhibits a misorientation slightly lower than $15^{\circ}$, indicating that the local deformation of the large particles, in particular, during preparation (especially during embedding at $453 \mathrm{~K}$ ), could lead to a progressive increase of low-angle boundary misorientation or eventually, static recrystallization. However, there is no indication that the high-angle boundaries originated from the heat treatment at 1023 K. As presented in Figure 4c, the aluminum particles exhibited a characteristically polycrystalline microstructure, which they acquired during the air-atomization production process due to quick solidification, caused by a unique combination of a low solidification point (933.5 K) and a high heat conductivity, which for liquid aluminum is equal to $89.9 \mathrm{~W} \cdot \mathrm{m}^{-1} \mathrm{~K}^{-1}$ immediately above the melting point (at $950 \mathrm{~K}$ ) [14]. However, in Figure 4d, the heat treatment performed at $1023 \mathrm{~K}$ disrupted this microstructure by melting the particles, and assured a suitable solidification environment for the growth of a limited quantity of crystals in each powder particle. Due to the slow cooling rate, the aluminum was kept in a slightly undercooled state for a relatively long time. Presenting the powder-blend processes at $1423 \mathrm{~K}$ was not possible since the compounds sintered together. 
The very low nucleation rate allowed the formation of only a limited number of crystals in each particle [22]. In many cases the particles obtained were monocrystalline. As presented in Figure 4a,b, the aluminum particles became spheroidal during the thermal process. Such a change also influenced the particle-size distribution (Figure 5): as the shape of the particles became increasingly spherical, their mean size decreased.

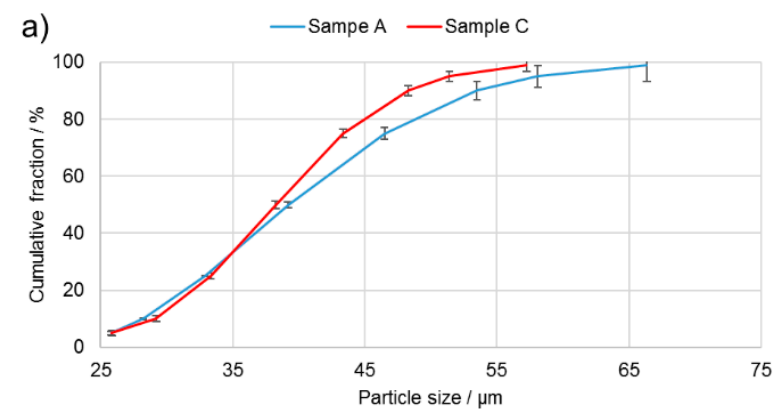

Figure 5. Comparison of cumulative particle-size distribution of samples A and C.

\section{Conclusions}

An aluminum powder of $99.7 \mathrm{wt} . \%$ purity was mixed with $20 \mathrm{wt} . \%$ of silica nanoparticles ( $400 \mathrm{~nm}$ ) and annealed at temperatures above the aluminum melting point-1023 and $1423 \mathrm{~K}$. Calorimetric studies showed the existence of a processing window where aluminum particles exist as liquid metal droplets separated by almost non-wettable silica particles. This allowed the surface tension to round the particles, which also caused a change in the particle-size distribution. Slow cooling provided the proper conditions for a low nucleation rate, which promoted the formation of a monocrystalline or nearly-monocrystalline structure of the powder particles. Annealing at $1023 \mathrm{~K}$ resulted in a slow redox reaction between aluminum and silica, leading to the formation of a small amount of Al-Si eutectics. Annealing the $\mathrm{Al}+\mathrm{SiO}_{2}$ blend above $1122.2 \mathrm{~K}$ results in an extensive reaction between aluminum and silica, leading to the diffusion of silicon into the aluminum.

In summary, the shape of aluminum particles was changed from a spattered to a spherical one in a controlled manner by means of surface tension, and the microstructure of the particles was changed to be monocrystalline, done simultaneously for the first time.

Author Contributions: Conceptualization, M.S. and C.S.; methodology, M.S., R.B., M.H., G.P., S.M.; validation, M.S., R.B. and M.H; formal analysis, M.S., C.S.; investigation, M.S., M.H., R.B., G.P., S.M; resources, C.S., G.P.; writing-original draft preparation, M.S., R.B., writing-review and editing, C.S., R.B., G.P., M.H, M.S., S.M.; visualization, M.S., R.B., S.M.; supervision, C.S., G.P.; project administration, C.S.; funding acquisition, C.S.

Funding: This research was funded by Graz University of Technology.

Conflicts of Interest: The authors declare no conflict of interest.

\section{References}

1. Ngo, T.D.; Kashani, A.; Imbalzano, G.; Nguyen, K.T.Q.; Hui, D. Additive manufacturing (3D printing): A review of materials, methods, applications and challenges. Compos. Part B Eng. 2018, 143, 172-196. [CrossRef]

2. Van Elsen, M. Complexity of Selective Laser Melting: A New Optimisation Approach. Ph.D. Thesis, Katholieke Universiteit Leuven, Belgium, Brussel, January 2007.

3. Schatt, W.; Wieters, K.-P. Powder Metallurgy: Processing and Materials; EPMA: Shrewbury, UK, 1997; ISBN 1-899082-05-50.

4. Jallo, L.J.; Schoenitz, M.; Dreizin, E.L.; Dave, R.N.; Johnson, C.E. The effect of surface modification of aluminum powder on its flowability, combustion and reactivity. Powder Technol. 2010, 204, 63-70. [CrossRef]

5. Nan, W.; Pasha, M.; Bonakdar, T.; Lopez, A.; Zafar, U.; Nadimi, S.; Ghadiri, M. Jamming during particle spreading in additive manufacturing. Powder Technol. 2018, 338, 253-262. [CrossRef] 
6. Zegzulka, J.; Gelnar, D.; Jezerska, L.; Ramirez-Gomez, A.; Necas, J.; Rozbroj, J. Internal Friction Angle of Metal Powders. Metals 2018, 8, 255. [CrossRef]

7. Spierings, A.B.; Voegtlin, M.; Bauer, T.; Wegener, K. Powder Flowability Characterisation Methodology for Powder-Bed-Based Metal Additive Manufacturing. Prog. Addit. Manuf. 2016, 1, 9-20. [CrossRef]

8. Zhang, L.P.; Zhao, Y.Y. Particle Size Distribution of Tin Powder Produced by Centrifugal Atomisation Using Rotating Cups. Powder Technol. 2017, 318, 62-67. [CrossRef]

9. Jedelský, J.; Jícha, M. Spray Characteristics and Liquid Distribution of Multi-Hole Effervescent Atomizers for Industrial Burners. Appl. Therm. Eng. 2015, 96, 286-296. [CrossRef]

10. Brunauer, S.; Kantro, D.L.; Wiese, C.H. The Surface Energies of Amorphous Silica; Manuscript received June 6, 1956; Contribution from the Portland Cement Association; Research and Development Laboratories: Chicago, IL, USA, 1956.

11. Keene, B.J. Review of data for the surface tension of pure metals. Int. Mater. Rev. 1993, 38, 157-192. [CrossRef]

12. Sobczak, N.; Sobczak, J.; Asthana, R.; Purgert, R. The Mystery of Molten Metal. China Foundry 2010, 7, 425-437.

13. El-Kareh, B. Fundamentals of Semiconductor Processing Technologies; Kluwer Academic Publishers: Dordrecht, The Netherlands, 1995; ISBN 978-1-4615-2209-6.

14. Leitner, M.; Leitner, T.; Schmon, A.; Aziz, K.; Pottlache, G. Thermophysical Properties of Liquid Aluminum. Metall. MatER. Trans. A 2017, 48, 3036-3045. [CrossRef]

15. Cheng, Z.; Lei, C.; Huang, H.; Tang, S.; Du, Y. The formation of ultrafine spherical metal powders using a low wettability strategy of solid-liquid interface. Mater. Des. 2016, 97, 324-330. [CrossRef]

16. West, R.R.; Gray, T. Reactions in Silica-Alumina Mixtures. J. Am. Ceram. Soc. 1958, 41, 132-136. [CrossRef]

17. Zykova, A.; Kazantseva, L.; Popova, N.; Vorozhtsov, A.; Kurzina, I. Influence of Modifying Mixtures on Si Crystal Formation in Al-7\%Si Alloy. Metals 2018, 8, 98. [CrossRef]

18. Yang, L.; Xia, M.; Li, J.G. Epitaxial Growth in Heterogeneous Nucleation of Pure Aluminum. Mater. Lett. 2014, 132, 52-54. [CrossRef]

19. Gorny, A.; Manickaraj, J.; Cai, Z.; Shankar, S. Evolution of Fe based intermetallic phases in Al-Si hypoeutectic casting alloys: Influence of the Si and Fe concentrations, and solidification rate. J. Alloys Compd. 2013, 577, 103-124. [CrossRef]

20. Wang, Z.; Wang, H.; Yang, M.; Sun, W. Thermal Reliability of Al-Si Eutectic Alloy for Thermal Energy Storage. Mater. Res. Bull. 2017, 95, 300-306. [CrossRef]

21. Finkelstein, A.; Schaefer, A.; Chikova, O.; Borodianskiy, K. Study of Al-Si Alloy Oxygen Saturation on Its Microstructure and Mechanical Properties. Materials 2017, 10, 786. [CrossRef] [PubMed]

22. Iqbal, N.; van Dijk, N.H.; Offerman, S.E.; Moret, M.P.; Katgerman, L.; Kearley, G.J. Real-time Observation of Grain Nucleation and Growth During Solidification of Aluminium Alloys. Acta Mater. 2005, 53, 2875-2880. [CrossRef]

(C) 2019 by the authors. Licensee MDPI, Basel, Switzerland. This article is an open access article distributed under the terms and conditions of the Creative Commons Attribution (CC BY) license (http:/ / creativecommons.org/licenses/by/4.0/). 